\title{
Involvement of males in promoting reproductive health
}

\author{
TMM Maja, D Litt et Phil \\ Nursing Department, Tshwane University of Technology
}

\section{Abstract: Curationis 30(1): 71-76}

At the international conference on Population and Development held in Cairo 1994, specific aspects of reproductive health addressed endorsed among others, were that unwanted pregnancies must always be given the highest priority and that every attempt should be made to eliminate the need for abortion.

This paper focused on the involvement of males in promoting reproductive health through prevention of unplanned and unwanted pregnancies. A total of 71 males (48 adults and 23 adolescents) were selected conveniently from two health care centres, North of Tshwane, Gauteng province. Structured questionnaires having open and closed questions were used for data collection.

Results indicated that most males (young and old) had general information about contraceptives and common side effects associated with contraceptive use. Despite this knowledge, only $(29,2 \%)$ adults and almost half the number $(50,0 \%)$ adolescents reportedly used condoms every time when having sex, whilst $(35,0 \%)$ adults and only $(13,6 \%)$ adolescents had never used condoms when having sex. Generally, males felt positive and wished to be involved in issues affecting their relationships, such as open communication about contraceptives used by their partners, discussing contraceptive problems together, planning families jointly with partner only, being informed about contraceptive failures and also playing a role in resolving such problems. Recommendations were made to encourage more visible involvement of males in promoting sexuality issues and reproductive health.

\section{Introduction}

The World Health Organization (WHO), other intergovernmental, international and bilateral organizations made a commitment to the principles of promoting reproductive health at the international conference on Population and Development in Cairo in 1994. Specific aspects of reproductive health endorsed at the conference indicate that prevention of unwanted pregnancies must always be given the highest priority and that every attempt should be made to eliminate the need for abortion. Good reproductive health should include freedom from risk of sexual diseases, the right to regulate one's own fertility with full knowledge of contraceptive choices and the ability to control sexuality without being discriminated against because of age, marital status, income or similar consideration (United Nations,
1994).

Unplanned and unwanted pregnancies pose major reproductive health problems to both women and men throughout the world, including the Republic of South Africa (RSA). The majority of these pregnancies are terminated either legally or mainly using illegalized procedures. In the United States of America (USA) and some Eastern European countries for which data are available, about half to three thirds of pregnancies are unplanned. In many developing countries, the proportion of births that are unintended exceeds $40 \%$; even in regions where families still want large families, 10 to $20 \%$ of births are unplanned (The Alan Guttmacher Institute (1997; Rosoff 1999:2). Estimates are that of the five million unsafe TOPs performed annually in Africa, these constitute $3 \%$ of all maternal deaths (WHO 1998:8). Prevention of unplanned 
and unwanted pregnancies could save countries money and other resources than caring for clandestine abortions or unwanted children. According to Varkey and Fohn (2000:8), in the RSA the government spends over R18,7 million annually to treat infections and complications associated with illegal TOPs.

Men are the main decision makers in most African countries and should therefore be involved in prevention of unplanned and unwanted pregnancies. Historically, limited attention and resources have been devoted to initiatives that emphasize men's constructive involvement in contraceptive practices and fertility issues (Bankole \& Singh, 1998: 15; Levack, 2000:7). One of the biggest problems is that men are left out of the picture when decisions about reproductive health issues are discussed. They are often marginalized by health services which do not have provision for males. The WHO (1998:9) emphasize that males should be empowered through the provision of information and services targeting boys, youth and adults within the home, communities and work settings. Young and old males must be educated about responsible sexual behaviour, treat women as equals and support efforts to respect women. The importance of male participation has become much greater with the emergence of the HIV/AIDS pandemic and the increasing prevalence of sexually transmitted diseases.

\section{Problem statement}

The failure of families and schools to educate youth including males about sex is a primary cause of unplanned and unwanted pregnancies. Even with sufficient knowledge of the means to avoid the pregnancy, women may continue to be victims of unwanted pregnancies if their male partners are not playing a positive role to prevent such pregnancies. Research pertaining to contraceptive practices focus on women and ignore males who could play a major role in promoting reproductive health. A study to determine the involvement of men in preventing unplanned and unwanted pregnancies became necessary.

\section{Purpose of the study}

The purpose of this research.was to determine the involvement of males in prevention of unplanned and unwanted pregnancies.

\section{Objectives}

The purpose of the research was addressed through the following objectives:

- $\quad$ Assess males' knowledge of and perceptions towards contraception.

- Ascertain efforts practiced by males in preventing unplanned and unwanted pregnancies.

- Determine reasons for non-use of contraceptives.

- Describe how males intended to be involved in preventing unplanned and unwanted pregnancies.

\section{Key Concepts}

Contraceptives are defined as agents used to temporarily prevent the occurrence of contraception, including oral pills, condoms, intra-uterine devices, diaphragm and injections (Ketting \& Visser, 1994:161).

Pregnancy implies the condition of a female after conception until the birth of the baby.

\section{Reproductive Health}

The WHO defines health as a state of complete physical, mental and social well being and not merely the absence of disease or infinnity. Reproductive health implies that apart from the absence of disease or infirmity, people have the ability to reproduce, to regulate their fertility, to practice and enjoy sexual relationships. It further implies that reproduction is carried to a successful outcome through infant and child survival, growth and healthy development. Finally, the concept of reproductive health is not limited to women, but also includes men (Fathalla, 1997:24).

Termination of pregnancy is defined as the abortion of a live foetus of a woman with the intent to kill such a foetus (Choice on Termination of Pregnancy Act 92 of 1996).

\section{Unplanned pregnancy}

Refers to a pregnancy that may occur accidentally without any intention. Most unplanned pregnancies often become unwanted and result in unintended births or are resolved by termination.

\section{Unwanted pregnancy}

Unwanted pregnancy is that pregnancy which may not have been planned, and that may be unintentional and unwelcomed by the pregnant woman.

\section{Research methodology}

The purpose of the research was addressed within a quantitative, exploratory and descriptive design to determine the involvement of males in preventing unplanned and unwanted pregnancies.

\section{Population and sample}

The target population for this research comprised all males who visited the health care centres to collect condoms as well as those accompanying their partners who came for contraceptive consultations.

As it was not possible to pre determine which clients would be visiting the health care centres during the period of data collection, a convenience sample was deemed the most ideal method to use. A convenience sample consists of selecting the most readily available or convenient persons or units for the sample (Polit \& Hungler 1999:281).

A total of 71 males, comprising of 48 adults and 23 adolescents participated in the study. Criteria for inclusion were:

- $\quad$ Males aged 16 to 55 years.
hales who visited the selected
condoms and those who
accompanied their partners for
contraceptive consultations.
Participants had to be residents
of Tshwane North, Gauteng
province.
Participation was voluntary.

\section{Research instrument}

Following a thorough literature review, a structured questionnaire was developed for data collection from males who visited the selected health care centres. The questionnaire included open and close ended questions covering:

- Biographic information which included respondents' age, marital status, level of education, religious affiliation and employment status.

- The number of children respondents had and how many children they wished to have. 
and perceptions about contraceptives.

Respondents' contraceptive practices

Intentions of their involvement in prevention of unplanned and unwanted pregnancies.

\section{Reliability and Validity of the research instrument}

Reliability of the research instrument refers to its stability, consistency or dependability in measuring the attributes it is designed to measure (Polit\& Hungler 1999:251). In this study, reliability was ensured by pre-testing the research instrument and addressing the concerns raised by respondents. The main concern was the contraceptive terminology which could not be translated directly into respondents' languages. The researcher then addressed this problem by availing self and trained research assistants to respondents during data collection to assist in clarification of contraceptive concepts and filling in answers for those who could not write.

Content validity was maintained through consultation with experts in reproductive health and research. Burns and Grove (2001:330) maintain that content validity is determined by ascertaining whether the measuring instrument includes all the essential elements relevant to the item being measured. An in-depth literature review was conducted and important aspects were included in the research instruments. A statistical analyst from the Medical Research Council (MRC) was engaged to assist in data analysis.

\section{Ethical considerations}

Written permission to conduct research was sought and granted from the authorities of the two health care centres selected for the study. Ethical approval was also obtained from the Ethics committee of UNISA prior to commencement of the research. Participation of respondents remained a voluntary process and they were informed of their right to withdraw from participating if they so wished without fear of being victimized. Confidentiality and anonymity were ensured throughout the research.

\section{Data collection}

The researcher and research assistants visited the selected health care centres on days of data collection and questionnaires were administered to respondents who met the selection criteria. Research assistants were informed to read questions to the respondents and fill in answers as stated to those who had problems in understanding contraceptive terminology even though the questionnaire was translated in Setswana, the predominant language spoken in the area.

\section{Data analysis}

Data was analysed using the Statistical Package for Social Sciences (SPSS) computer programme with the assistance of a statistical analylist from the MRC.

\section{Results and Discussion}

\section{Demographic data}

Respondents' ages ranged from 16 to 55 years involving 48 adults and 23 adolescents. A total of 27 adults were married, $18(37,5 \%)$ adults and $22(95,7)$ adolescents were single whilst $2(4,2 \%)$ adults and one $(4.3 \%)$ adolescent were cohabiting. Most respondents 37 (52,1\%) adults and $13(56.5 \%)$ adolescents had obtained Grade 12 whilst $10(43,5 \%)$ adolescents were still schooling. A significant number of $41(63,4 \%)$ males had fulltime or mainly part-time jobs, whilst $7(14,6 \%)$ were unemployed. Respondents affiliated to various religions, mostly Apostolic, Methodist, Jehovah's witness, ZCC and Catholic. Certain religions have specific practices which they require of their followers and these impacted on effective use of contraception either positively or negatively.

\section{Number of children respondents had and wished to have}

A total of $27(38,0 \%)$ males had no children, $24(33,8 \%)$ males had two children each, and only one adult male had five children. Two (4.2\%) adolescents admitted having two children, whilst $3(8.7 \%)$ had three children each. Although most respondents had only one or two children each, no conclusion could be drawn about the ultimate number of children they would have as a further majority were not married and could still wish to have children after marriage. Of particular concern was the number of adolescents who already had two and three children in spite of the freely available contraceptives. In response to how many children respondents wished to have, slightly more than half the numbers 25 $(52,1 \%)$ adults and $12(52,2 \%)$ adolescents preferred having fewer children mainly to have better lives and afford the high cost of living.

\section{Knowledge and Sources of information about contraception}

Most adults $44(87,3 \%)$ and $16(76,2 \%)$ adolescents had general knowledge about some methods of contraceptives such as the pill, injection and mainly condoms, as well as side effects commonly experienced by their partners. Common side effects mentioned were weight gain of partners, excessive bleeding or no menstruation at all when using the pill leading to infertility.

Regarding sources of information, the media seemed to have been the main source of information as stated by 26 $(54,2 \%)$ respondents followed by 11 $(22,8 \%)$ who rated teachers as the second important source of information. Only 2 $(4,2 \%)$ adolescents indicated that their sisters and nurses were their least important sources of contraceptive information. Nurses are well placed in specific womens' health, general, occupational and school health settings to be informed providers of information regarding contraception and should therefore play a major role in this aspect. None of the adolescents had received contraceptive information from their brothers and fathers. Involvement of males in sharing such information to their sons could help reduce the levels of unplanned and unwanted pregnancies, STDs and HIV/AIDS. Fathers and brothers could explain better about the correct use of condoms ( Sharma, Dave, Sharma \& Chauhan 1997:712).

\section{Respondents' perceptions towards contraception}

Over half the number of $26(55,0 \%)$ adults and almost $15(68,2 \%)$ adolescents were positive about contraception; only 4 $(10,0 \%)$ adults and $2(12,0 \%)$ adolescents had ambivalent perceptions towards contraception whilst $13(35,0 \%)$ adults and only $3(20,0 \%)$ adolescents felt negative about contraception. Although a considerable number of males felt positive about contraception, more adequate information could allay fears and misconceptions associated with contraceptives (Hatcher et al 1997:1-14; Sharma et al 1997:712). Chipfakacha (1993: 82) noted that even though men in 


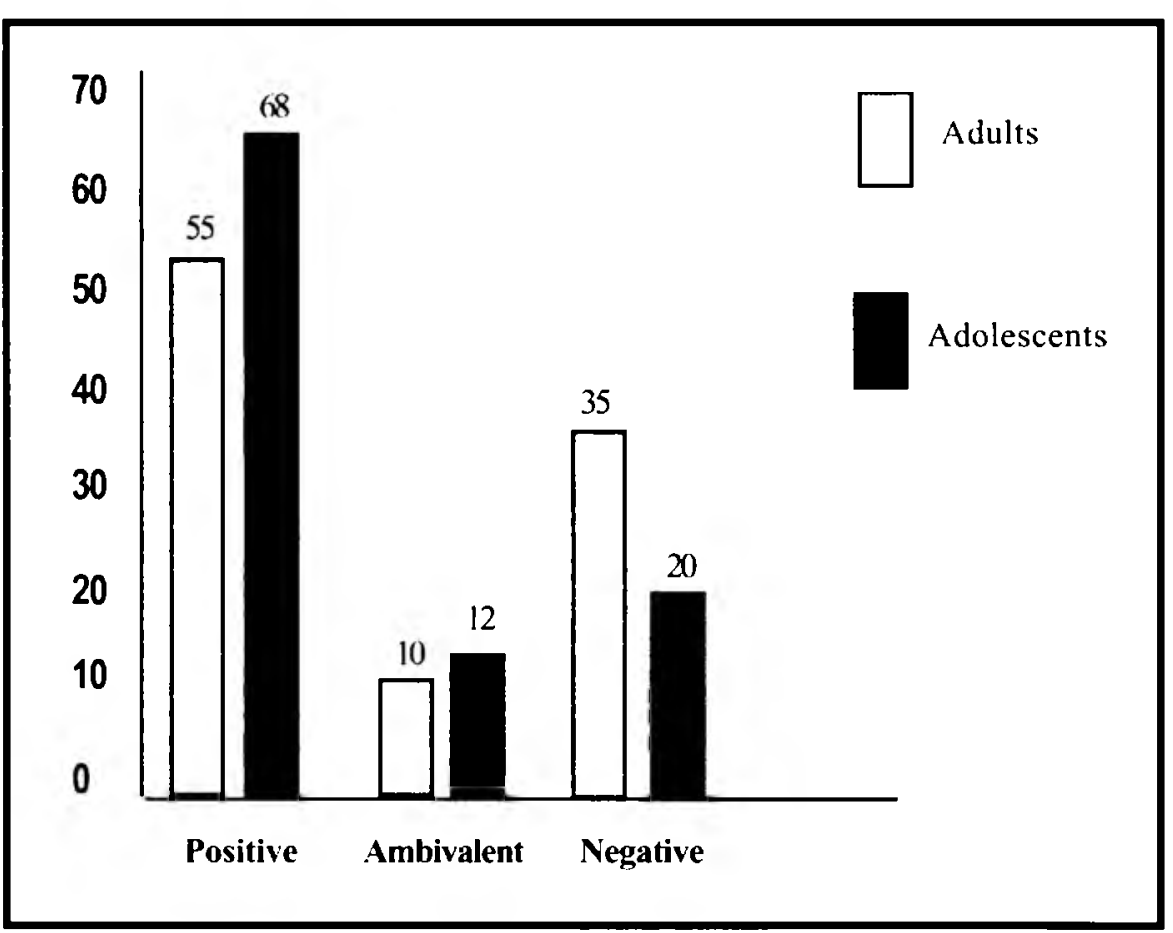

their study were informed about contraception, the majority of $65 \%$ would not discuss family planning issues with their wives, some even to the extent of displacing aggression towards their wives and children.

\section{Contraceptive practices, availability and frequency of condom use}

Effective and regular condom use when having sex could reduce high levels of unplanned and unwanted pregnancies with concomitant complications. Out of 71 males, $36(70,5 \%)$ adults and $15(68,2 \%)$ adolescents used condoms; 3 (16,1\%) adults and $2(9,1 \%)$ adolescents were using the withdrawal method; only 3 $(4,3 \%)$ adults had been sterilized and had visited the clinics to get condoms for protection against STDs and HIV/AIDS.

Regarding the availability of condoms, the majority of $53(77,9 \%)$ respondents always received condoms when needed from health care services. However, only

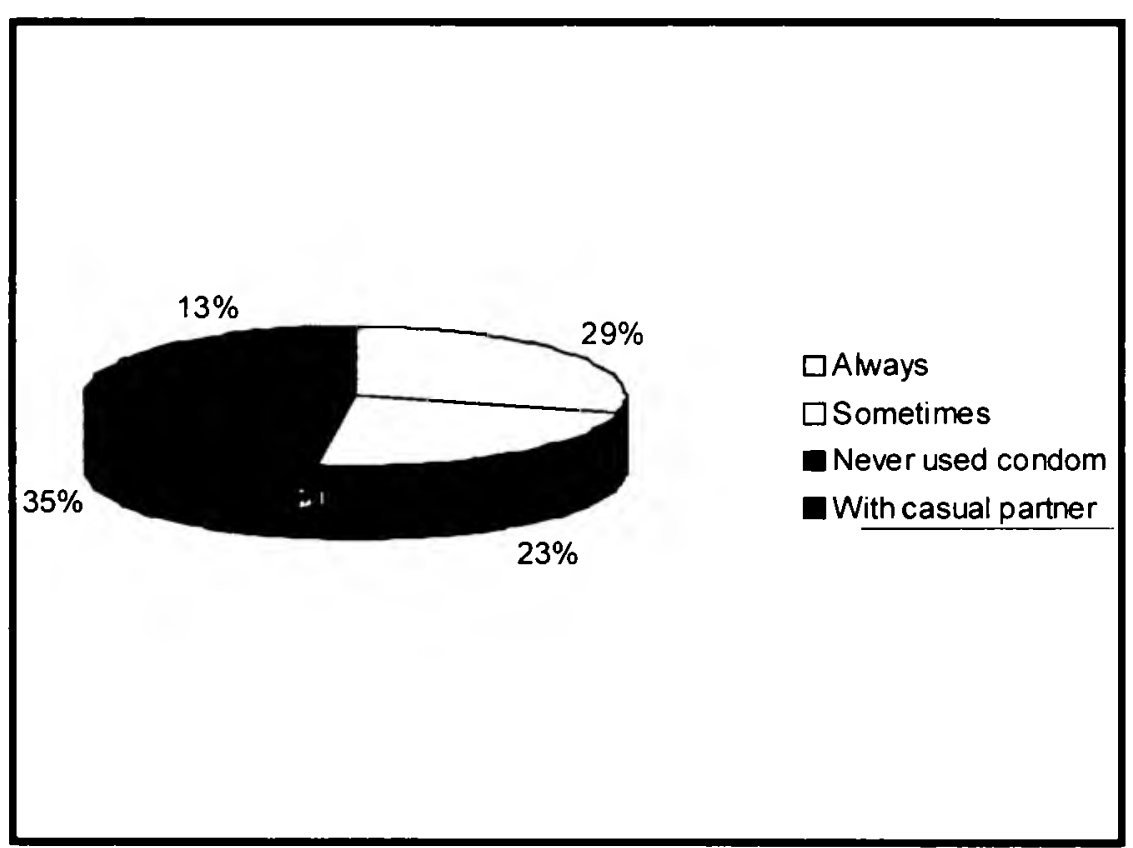

Figure 2 : Condom use by adult males
$14(29,7 \%)$ adults and almost half the number of $11(50,0 \%)$ adolescents admitted to using condoms every time when having sex; $11(22,9 \%)$ adults and $6(27,2 \%)$ adolescents used condoms sometimes; $6(12,5 \%)$ adults and $2(9,0 \%)$ adolescents used condoms when having sex with a casual partner whilst $17(35,4 \%)$ adults and only $3(13,6 \%)$ adolescents had never used condoms when having sex. Refer to figures 2 and 3 for these findings.

These findings suggest that in spite of the freely available condoms, respondents could not use them effectively to prevent unplanned and unwanted pregnancies. Similarly, in India, Sharma et al (1997:709) noted that 74,0\% sexually active men had ever used condoms when having sex, $24 \%$ were irregular users and only $1,8 \%$ reported regular use of condoms. Peltzer (2001:55) reported that among the first year students at the university of the North. RSA, almost $29,2 \%$ had never used condoms, $35 \%$ always used condoms, $19,8 \%$ did so regularly and $8,5 \%$ used condoms irregularly over a three month period.

These results seem to correlate with those reported in previous studies. If used properly, comdoms have been documented to be fairly reliable method of contraception and offer protection against STDs (de Wet et al 2002:10; Silberschmidt \& Rasch 2001:1815). When issuing comdoms to clients, health care professionals should emphasize that comdoms must be used consistently when having sex. Both males and females must know how and when to put on comdoms to ensure their effectiveness.

\section{Reasons for non-use of condoms}

Respondents cited various reasons for non-utilization of condoms. Partner trust was reported by $16(33,3 \%)$ adults and 7 $(32,0 \%)$ adolescents; diminished sexual satisfaction $12(25,0 \%)$ adults and 8 $(34,0 \%)$ adolescents; condom breakages $10(20,2 \%)$ adults and $6(30,0 \%)$ adolescents; lack of skill in using condoms $8(18,2 \%)$ adults and $3(15,0 \%)$ adolescents.

\section{Respondents' intentions of involvement}

A significant number of $62(88,9 \%)$ respondents stated their intentions to be involved in preventing unplanned and unwanted pregnancies as depicted in 


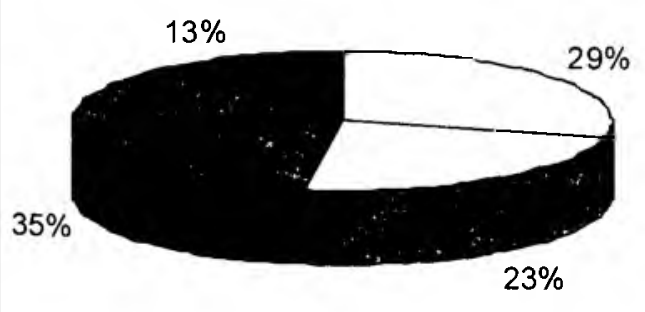

$\square$ Always

$\square$ Sometimes

Never used condom

With casual partner

\section{Figure 3 : Condom use by adolescent males}

Table 1. Almost 56 (78,8\%) respondents regarded open communication with partners in matters affecting their relationship as paramount to promoting reproductive health. Women are often unable to discuss safer sex with their partners because of gender imbalances and powerlessness. Karin (1995:1521) noted that women need communication skills to enable them to discuss sexual and other issues with their partners. A total number of $53(74,6 \%)$ respondents wanted to share information about contraceptives with their partners; 52 $(73,2 \%)$ wanted to know contraceptive method(s) used by partner; whilst 48 $(67,7 \%)$ respondents intended to be informed when there are problems related to contraception which could lead to an unplanned pregnancy; and 46 (74,2\%) respondents urged their partners to involve them when resolving problems of an unplanned pregnancy, whilst 40 $(64,5 \%)$ respondents wished to be more informed about reproductive health issues.

These findings seem to be consistent with the results of a British survey conducted to establish mens' views on male hormonal contraception at a fitness centre in Bristol. A total of $81 \%$ of men stated that birth control is a shared responsibility of both partners. The authors added that men are already involved in family planning despite the few contraceptive options available (Brooks, 1998:7). In the RSA, Myburgh, Gmeiner and Van Wyk (2001:38) found that biological fathers of their partners' unwanted pregnancies expressed powerlessness related to having a decision of termination of pregnancy and experienced a turmoil related to the impact of the decision on interpersonal and intrapersonal relationships.

\section{Conclusion and \\ recommendations}

The study results permits the conclusion that males, young and old need to be adequately informed about reproductive health issues. Such information could improve their perceptions about contraceptives positively and thus play a better role in preventing unplanned and unwanted pregnancies.

Males should be empowered through the provision of information and services targeting youth and males within the home, communities and work settings. Although a significant number of males had knowledge about contraceptives including condoms, few had ever used them consistently to prevent unplanned and unwanted pregnancies. Reasons provided by respondents for non-use of condoms imply that much still needs to be done to get more involvement of males in reproductive health. Recommendations include involving males (health care providers) in family planning services, open communication about reproductive health issues starting from homes, and schools to dispel myths associated with prevention of unplanned pregnancies. Further research is needed to clarify and explore from males contributions they could make to improve reproductive health.

\section{References}

THE ALAN GUTTMACHER INSTITUTE.1997. Family planning improves child survival and health issues in brief. New York.

\section{Table 1: Respondents' intentions to be involved in unplanned pregnancies}

\begin{tabular}{|l|l|l|}
\hline Respondents' intentions of involvement & Frequency & Percentage \\
\hline Open communication with “my" partner about “our" relationship. & $\mathbf{5 6}$ & $\mathbf{7 8 , 8}$ \\
\hline Sharing information about contraception and which method my partner is using. & $\mathbf{5 3}$ & $\mathbf{7 4 , 6}$ \\
\hline Discussing contraceptive problems together and allowing me to play a role. & $\mathbf{5 2}$ & $\mathbf{7 3 , 2}$ \\
\hline Sceking advice together when there are problems regarding partner's health. & $\mathbf{4 8}$ & $\mathbf{6 7 , 7}$ \\
\hline Being informed about contraceptive failure resulting in unplanned pregnancy. & $\mathbf{4 6}$ & $\mathbf{6 4 , 7}$ \\
\hline Resolving problem of unplanned pregnancy together. & $\mathbf{4 2}$ & $\mathbf{5 9 , 3}$ \\
\hline Need more information about reproductive health. & $\mathbf{4 0}$ & $\mathbf{5 5 , 6}$ \\
\hline
\end{tabular}

